\title{
An analysis of calendar data: examining contraceptive use dynamics in Uganda
}

\author{
Peter Kisaakye and Tom A. Moultrie \\ Centre for Actuarial Research, University of Cape Town \\ KSKPET001@myuct.ac.za
}

\begin{abstract}
The analysis of contraceptive calendar data offers a valuable and useful approach to enhancing our understanding of patterns of contraceptive use in the developing world. Effective use of modern contraception is believed to be the surest way to plan for births and avert unwanted fertility. Despite the role that contraception plays in reducing fertility, sexually active women (especially those in subSaharan Africa), continue to grapple with unwanted and mistimed pregnancies. In many instances, this results in unsafe induced abortion, with its attendant risks to maternal health. Sub-optimal use of contraception is likely to attenuate fertility transition in the region. Using calendar data from two Demographic and Health Surveys conducted in Uganda, we adopt a longitudinal approach to examine method discontinuation and switching patterns following stopping use of a contraceptive method. Discontinuation of methods was more pronounced among women using the pill and injection. The findings provide a basis for a discussion on the implications of reproductive behaviour in sub-Saharan Africa.
\end{abstract}

Key words: Calendar data, discontinuation, switching, Uganda

Peter Kisaakye is a doctoral student at the Centre for Actuarial Research, University of Cape Town. Tom A Moultrie is professor of demography and director of the Centre for Actuarial Research, University of Cape Town.

\section{Introduction}

The adoption and effective use of modern contraception is expected to lead to lower fertility especially in the developing world. In sub-Saharan Africa, where most countries are still far from registering replacement level of fertility, a significant proportion of women are still not using modern methods of contraception despite almost universal awareness. Many women still use traditional methods with high failure rates (Marston and Cleland 2003).

In Uganda, the Demographic and Health Survey (DHS) reports have consistently found almost universal knowledge of modern contraceptive methods although this has not translated in practical use. For example, the 2012 Uganda Demographic and Health Survey (UDHS) reports knowledge of a contraceptive method to be 98 percent. Yet the contraceptive prevalence rate is about 30 percent (Kabagenyi, Ndugga, Ojiambo et al. 20/4b). Lack of motivation to use modern methods could be a significant contributory factor in explaining the gap between knowledge and awareness (Curtis, Evens and Sambisa 20II). In many analyses, attention is directed to measures of contraceptive prevalence: the proportion of women currently using modern contraception. However, the estimates of Contraceptive Prevalence Rates (CPR) presented in DHS reports are cross-sectional and cannot describe the changing patterns and methods of contraception of individual women. In Uganda where the CPR remains low ( 30 percent) and where fertility transition is slow and even slower in rural areas, with a national total fertility rate of 6.2 children per woman - (Uganda Bureau of Statistics (UBOS) and ICF International Inc 20I2), the use of crosssectional estimates to study the relationship between the distal factors and contraceptive use on fertility outcomes may obscure our understanding of fertility transition. By contrast, the analysis of calendar data offers the possibility to understand method choice, discontinuation, and switching patterns, which can offer significant insights into demographic phenomena as well as impact on policy (Laguna, Po and Perez 2000).

Women are likely to discontinue use of a method for several reasons. Again, cross-sectional data only provide a snapshot rather than telling us 
the switching patterns from one method to another (Curtis and Hammerslough 1995). Crosssectional data also limit our understanding of the methods that women are most comfortable with using. Consequently, the evidence-base for programme and policy development in contraceptive use campaigns is compromised.

In this study, we adopt a longitudinal approach using time-to-event history models to examine contraceptive use patterns among Ugandan women. Our main contribution of this study is our identification of the discontinuation and switching patterns of contraceptive use among Ugandan women from a longitudinal perspective. Specifically, we examine the relationship between contraceptive method discontinuation at 12 months after initiation, method switching and the median duration of use by women's education and type of place of residence.

The literature on contraceptive use has documented several reasons why women choose not to use a method or else discontinue use of a method. Bradley and colleagues (2009) group the reasons for discontinuation in seven mutually exclusive and exhaustive ways. The first six categories relate to women in need of contraception. These six categories are method failure (measured by a woman getting pregnant while using a method); health concerns or side effects; method related reasons to include switching to a more effective method or inconvenience with use of a method; costs and accessibility; husband's opposition to use a method; and other related reasons such as desire for more children. The last category consists of women who are not in need of contraception. Such women desire to get pregnant, and also cite reasons such as infrequent sex, husband away, marital dissolution, difficult in getting pregnant or reaching menopause as reasons leading them to stop using a contraceptive method.

Curtis and Hammerslough (1995) point out that use of a method largely depends on its quality, convenience, availability, cost and side-effects, as well as the effects of the mass media, and rumours. Discontinuation, or inefficient use, of methods may lead to mistimed and unplanned pregnancies (Barden-O'Fallon, Speizer and White 2008). Moreover, discontinuation is likely to be underreported due to stigma and the fear of being labelled failures at using modern contraceptives effectively. In such instances, women may be compelled to report unintended or mistimed pregnancies as wanted pregnancies especially in places where abortion is taboo or stigmatised
(Bradley, Schwandt and Khan 2009; Curtis, Evens and Sambisa 20I I).

However, as Curtis and Hammerslough (1995) argue, stopping use of a method may largely depend on the characteristics of a user. For example, discontinuation patterns are likely to differ by type of place of residence and education background. These two socioeconomic factors are argued to be among the most important distal determinants of fertility transition in sub-Saharan Africa (Caldwell 1980; Garenne and Joseph 2002; Bongaarts 2010).

In this paper, we investigate whether women who reside in rural areas are less likely than their counterparts in urban areas to use modern contraceptive methods. We also seek to test if rural women are more likely than those in urban areas to discontinue use of a method. Based on the challenges faced by women especially in rural areas such as travelling long distances to health centres for services, method availability among others (Skiles, Cunningham, Inglis et al. 2015), we anticipate that women in rural areas are likely to discontinue use of a method. Finally, we investigate whether women with higher educational attainment are more likely to continue use of a method than their counterparts with less education.

\section{Literature review}

Globally, the Contraceptive Prevalence Rate (CPR) among married women has almost doubled from 36 percent in 1970 to about 64 percent in 2015 (United Nations Population Division 2015d). The promotion of family planning services is essential in realising lower fertility levels especially in the developing world with slow fertility transition (Tsui 200I). A small proportion of women using modern contraception in the developing countries means that, unplanned pregnancies and induced abortions are inevitable (Darroch 20/3). Effective use of modern contraception has the potential of improving women's health and that of their children, improving their decision making, and enabling better participation in healthy job opportunities (Habumuremyi and Zenawi 20I2).

In an effort to curb population growth in the sub-Saharan African region, and reduce fertility levels substantially to lower levels, family planning programmes geared toward contraceptive uptake have intensified in the region (Darroch and Singh 2013). Seltzer (2002) observes that excessive population growth led to the introduction of family planning programmes in the developing world.

Seltzer (2002) documents three reasons why contraceptive uptake has not been as great as 
hoped. First, there is a lack of consensus on the best direction to take in reducing high fertility levels. Some advocate the promotion of family planning whilst others argue for improving women's status through uplifting their education levels. For instance there is evidence provided of how mass education was instrumental in reducing high fertility in the developing world (Caldwell 1980).

A study about the link between education and fertility in 22 sub-Saharan African countries came to the conclusion that, an increase in the aggregate level of education has the potential of reducing high fertility rates (Kravdal 2002). But these are not contradictory: better educated women are more likely to use modern contraception because they can access more information about contraceptive technologies and also have more autonomy over reproductive decisions (DeRose and Ezeh 20l0).

Second, some advocate for an increase in the supply of contraceptive products whilst others support the idea of improving on the quality of contraceptives, while Seltzer's third explanation is that couples often find it a challenge to discuss family planning topics and issues surrounding birth control practices especially in the African context. These problems have made the promotion and use of modern contraception challenging (Seltzer 2002).

The East African region is one of the regions with the highest fertility and unmet need for family planning, yet contraceptive use is low. According to the estimates from the UN Population Division, current contraceptive use of modern methods in Uganda has increased from eight percent in 1995 to 26 percent in 2014 (United Nations Population Division 2015a).

The study of contraceptive use dynamics provides a basis for understanding the patterns of contraceptive use, and hence the success or failure of family planning programmes. Contraceptive use dynamics refer to method failure, method switching, and method discontinuation. Women who report becoming pregnant whilst using a method are categorised as having experienced a method failure. Discontinuation of a contraceptive method refers to the deliberate stopping of a contraceptive method after use for some time, whilst method switching entails the changing of methods (from a previous method to a new method). Whereas method discontinuation can be used as a measure of how satisfied users are with a particular method, method switching provides an indication of a method mix available to choose from (Ping 1995). Method discontinuation can also provide an idea of how well family planning services are delivered to users as well as contraceptive supply dynamics (Blanc and Way 1998).

It is important to note, however, women's continued use of a particular method may not necessarily imply method satisfaction (Ali and Cleland 1995) but rather a lack of alternative and effective contraceptive methods. Similarly, a wide range of contraceptive methods coupled with wellinformed contraceptive users is likely to lead to more frequent switching of contraceptive methods (Bruce 1990). The study of contraceptive use dynamics reflects the progress made by family planning programmes and assists in identifying problems that need redress to achieve wider coverage and increased uptake (Ali, Cleland and Shah 20I2).

\section{Theoretical framework}

The framework for this study (Figure I), adapted from Moultrie and Timæus (2015), provides theoretical and hypothesized interlinkages between different sets of variables. Moultrie and Timæus demonstrate how individual- and population-level factors can be located within the standard framework of fertility (Moultrie and Timæus 2015). This study builds on a set of concepts from their framework.

Examples of the distal determinants included for analysis are age, educational attainment and type of place of residence. Our inclusion of the residence variable in our analyses is based on established findings that most sub-Saharan African countries have had a similar fertility transition by type of residence, which is usually lower in urban areas than in rural areas (Garenne and Joseph 2002). We also include the age of a woman in the analyses as contraceptive dynamics are likely to be strongly associated with age (Allendorf 20/2).

The mediating strategies inform the underlying reasons for the use of contraception: spacing, postponing, and limiting future births (Timæus and Moultrie 2008). The proximate factors are the immediate factors that influence contraceptive use dynamics for example, fertility preferences and contraceptive knowledge. The outcome factors are method switching, failure, and stopping use. 
Figure I: A theoretical framework model showing hypothesised interrelationships between the distal and outcome factors

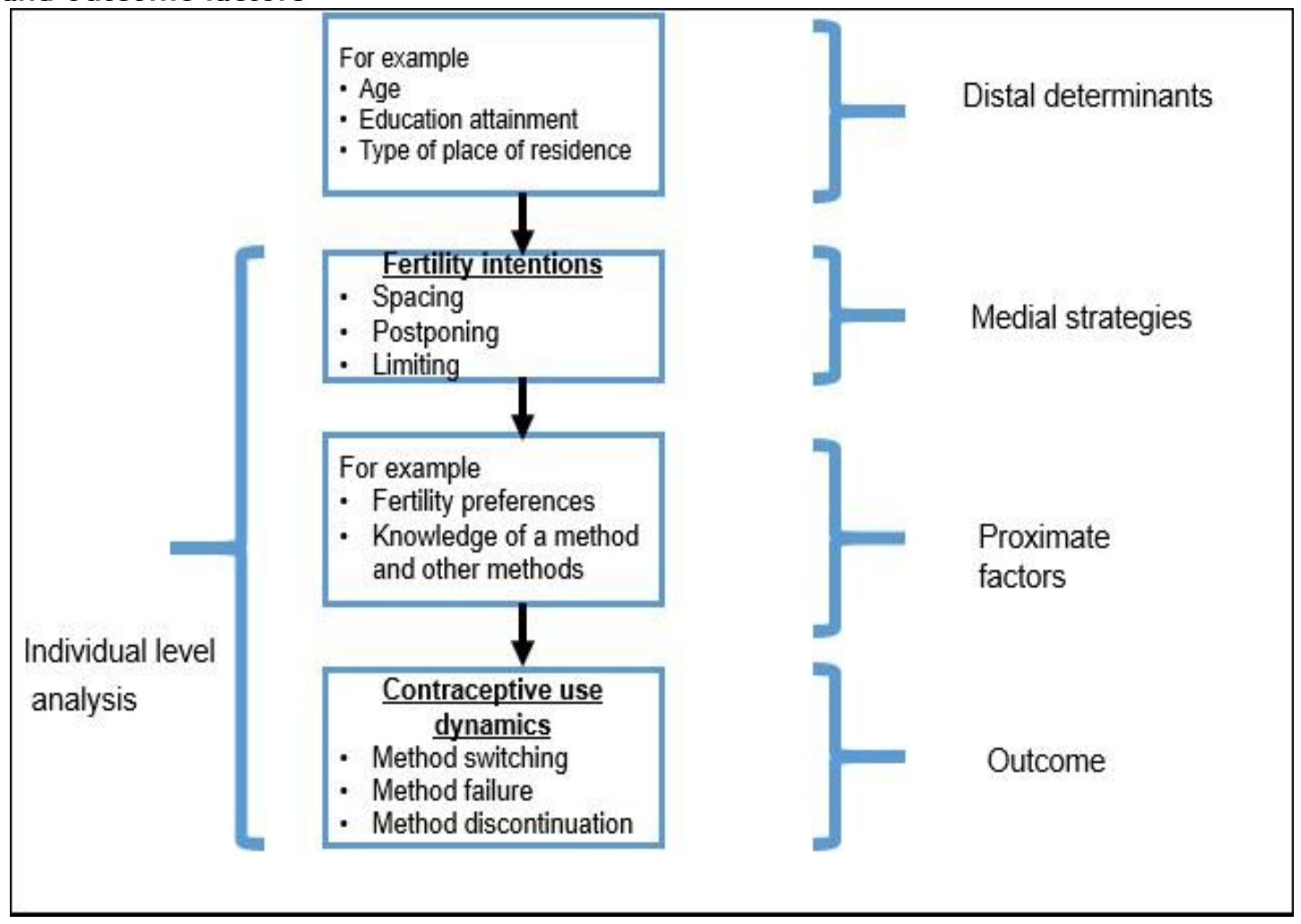

Source: Adapted from the theoretical framework (Moultrie and Timæus 2015).

\section{Data and methods}

\section{Source of data}

We use data from the 2006 and 2011 Uganda Demographic and Health Surveys (DHS). The demographic and health surveys are the primary source of data on patterns and trends of contraceptive use. These surveys use nationally representative samples which aim to provide upto-date information on fertility, mortality, maternal and child health, knowledge and contraceptive use, nutrition, and HIV/AIDS. The surveys permit comparability across both time and space because of the standard instrument used to collect data. The surveys use a stratified, clustered sampling design to select the households for interview (Uganda Bureau of Statistics (UBOS) and ICF International Inc 2012) and interviews all women aged 15-49 in selected households.

In the 20II Uganda DHS (UDHS) 8674 women were interviewed whilst the 2006 survey collected information from 8531 women. We limit the sample to all married women (including those living with a partner) to obtain a weighted sample of 5352 and 5362 in the 2011 and 2006 surveys respectively aged 15-49. We adopt this criterion because of the underlying assumption that most sexual activity occurs among married women. And since the principal focus of our enquiry is to examine patterns of contraceptive use dynamics, we filtered out women who have never used a method to either limit or delay further child bearing because they would not contribute to the calendar data trajectory. This left us with a weighted number of 2834 and 2622 married women from the 201I and 2006 surveys respectively.

The contraceptive calendar collects information on episodes of use of methods as well as non-use. This information is recorded on a month-by-month basis (Ali, Cleland and Shah 20I2). In each month, the calendar data reflects the method of contraception used and - if this is not the same method as that used in the previous month - the reason for discontinuation of the previous method. The calendar is structured in a way that facilitates respondents to sequence events that happened at a particular point in time thereby to reduce recall errors (Callahan and Becker 20I2). Each of the contraceptive methods is given a letter code which interviewers enter in a box corresponding to the month of use. The calendar also reports periods of pregnancy, birth as well as terminated pregnancy although there is no distinction made between spontaneous and induced abortion (Ali and Cleland 2010a). 


\section{Methods and analyses}

We adopt a longitudinal approach using time-toevent history techniques to model contraceptive discontinuation among Ugandan women using information collected retrospectively for a period of five years prior to each survey. For example, for the 20ll survey, the information collected starts from Ist January 2006 up to the time of the survey date. This means that our analyses span a period of ten years.

However, different women may have different exposure time to the risk of discontinuation of a method because of the varying dates of interview (Bradley, Schwandt and Khan 2009). For this reason, we have opted to standardise the period of exposure by first, limiting the analysis to 60 months before the survey date and also truncating the data to a point 3 months before the survey because of severe under-reporting of first trimester pregnancies (Ali and Cleland 1995). The main reason for applying left censoring to our sample is to avoid the selection bias that might emerge from capturing long episodes that would occur for more than 5 years before the survey (Ali and Cleland 1999).

Survival analysis is a powerful tool that can be used to analyse information collected retrospectively - analysing the survival time to the occurrence of an event of interest. In the context of this paper, our focus is on the time it would take a woman to either discontinue use of a method either intentionally or unintentionally before the next event occurs or the time it takes her to switch from one method to another.

For analysis, we follow an episode approach. An episode is a period of uninterrupted use or non-use of a contraceptive method (Ali and Cleland 20l0b). In this case, one woman could have multiple episodes of contraceptive use across the entire calendar period. We make use of non-parametric models because of the advantage they have in handling discrete time survival data. This is because of the fact that the information about duration of contraceptive use is collected and recorded to the nearest whole number (Ali and Cleland 1999).

Non-parametric models make no assumption about the distribution of failure times and the effect of the covariates on survival experience. Instead, the data are left to speak for themselves (Cleves, Gould, Gutierrez et al. 2010). We present KaplanMeier estimates depicting the occurrence of the event of interest. These estimates can also be used to compare the survival experiences of the distal determinants and are appropriate for handling censored data (Cleves, Gould, Gutierrez et al. 2010). All the results presented are adjusted to take care of the appropriate weights (including the complex sampling survey weights) for representativeness to the whole population and also for appropriate adjustments for non-response and missing values.

Although calendar data carry the risk of recall bias brought about by the heavy burden placed on respondents to report events that occurred far back in the past, the data are generally considered to be of good quality to draw robust conclusions (Steele and Curtis 2003; Cleland and Ali 2004). Duration heaping of method use and omission of events from the calendar (which could be either accidental or deliberate) have been highlighted in the demographic literature (Curtis and Hammerslough 1995; Ali, Cleland and Shah 2003). Nonetheless, these drawbacks have been reported to have a minimal effect on the estimates of contraceptive discontinuation.

\section{Limitations of the study}

We highlight two main limitations to this study. First, although the calendar data approach offers the unique benefit of examining contraceptive use from a longitudinal perspective to track changes in contraceptive use patterns over time, the two distal determinants (education and type of place of residence) included in the analyses are assumed to be invariant with time yet women might have changed either their place of residence or education status in the five years prior to the survey. This means that the relationship between these variables and reported contraceptive use is not casual but rather an association.

The second limitation is about the information collected on barrier methods such as condoms. Although the information on the frequency of condom use has been argued to be the most accurate measure for predicting pregnancy outcomes (Minnis, Straten, Gerdts et al. 2010), there is no effort done to get information about the number of times a condom is used in a month (in the calendar) each time the couple has had a sexual encounter. Nor does the DHS solicit information from respondents about the frequency of sexual intercourse (Meekers and Rossem 2005).

We therefore draw an assumption that a couple used a condom throughout the entire period (month) they had sexual intercourse. However, use and interpretation of such information has to be done cautiously since the data may be inconsistent leading to biased results. As some authors have noted, self-reported data on condom use may not be free from recall bias and social desirability (Reynolds, Luseno and Speizer 20I2). Using data from six DHS surveys, Meekers and Rossem (2005) 
found the relationship between the number of times couples have sexual intercourse and use of condoms varied.

\section{Results}

The descriptive results show that knowledge of a contraceptive method is nearly universal with about 97 percent of married women reporting knowledge of at least one modern contraceptive method. However, awareness does not translate directly into use as a significant proportion of married women are still not using a modern method to either delay or avert unwanted pregnancies.

The results in Table I show that about half of these married women have never used a contraceptive method to either delay or avoid getting pregnant. This estimate shows a slight decrease of such women by about four percent from 2006 (see Table I). Moreover, about 70 percent were not using a method at a time of data collection in the 201 I survey. Although this estimate is a snapshot in time, we note a decrease of about seven percent in the proportion of women who are not using a contraceptive method at a time of data collection between the 2006 and 20I I surveys. As expected a small proportion of young women in the age group 15-19 had ever used a method of contraception probably because a small proportion of them have initiated child bearing.

Table I: Percentage distribution of married and cohabiting women who have ever used a modern method to avoid or delay further child bearing by age group, Uganda Demographic and Health Surveys

\begin{tabular}{|c|c|c|c|c|c|c|c|c|}
\hline \multirow{3}{*}{$\begin{array}{l}\text { Age } \\
\text { group }\end{array}$} & \multicolumn{4}{|c|}{ Ever use of method } & \multicolumn{4}{|c|}{ Current use of method } \\
\hline & \multicolumn{2}{|c|}{2006} & \multicolumn{2}{|c|}{2011} & \multicolumn{2}{|c|}{2006} & \multicolumn{2}{|l|}{2011} \\
\hline & No & Yes & No & Yes & Not using & Using & Not using & Using \\
\hline $15-19$ & 64.2 & 35.8 & 73.6 & 26.5 & 89.2 & 10.8 & 86.7 & 13.4 \\
\hline $20-24$ & 48.7 & 51.3 & 51.5 & 48.5 & 79.0 & 21.0 & 77.1 & 22.9 \\
\hline $25-29$ & 47.0 & 53.1 & 42.0 & 58.0 & 77.3 & 22.7 & 69.2 & 30.9 \\
\hline $30-34$ & 47.2 & 52.8 & 39.0 & 61.0 & 74.9 & 25.1 & 66.2 & 33.8 \\
\hline $35-39$ & 50.7 & 49.3 & 41.3 & 58.7 & 76.3 & 23.7 & 64.3 & 35.7 \\
\hline $40-44$ & 54.4 & 45.6 & 43.2 & 56.4 & 72.1 & 27.9 & 63.6 & 36.4 \\
\hline $45-49$ & 61.5 & 38.5 & 60.1 & 40.0 & 79.3 & 20.7 & 80.6 & 19.4 \\
\hline Total & 51.0 & 49.0 & 47.0 & 53.0 & 77.6 & 22.4 & 71.1 & 28.9 \\
\hline
\end{tabular}

Analysis of calendar data

Table 2 presents discontinuation rates at 12 months after starting use of a modern method. Using the $201 \mathrm{I}$ estimates, the results in Table 2 indicate that the injectable method constitute the highest proportion of married women who stopped using after 12 months. By contrast, estimates from the 2006 survey show that almost every married woman had stopped using a condom after 12 months. Discontinuation of modern reversible methods seems to be a major problem among Ugandan married women as a significant proportion stopped use of a modern method after 12 months.

Table 2: Contraceptive prevalence and proportion stopped using at 12-months among married and cohabiting women age 15-49, Uganda

Method Percentage of married women using Proportion stopped using at 12 months a modern method

\begin{tabular}{lllll}
\hline & 2006 & 2011 & 2006 & 201 I \\
\cline { 2 - 5 } Pill & 2.9 & 2.9 & 73.2 & 66.0 \\
IUD & 0.2 & 0.5 & - & 38.8 \\
Injection & 10.3 & 14.1 & 79.2 & 68.3 \\
Condom & 1.7 & 2.7 & 88.8 & 24.4 \\
Sterilisation & 2.4 & 2.9 & - & - \\
Other modern & 1.4 & 3.2 & 25.0 & 31.1 \\
Total & 18.9 & 26.3 & 75.3 & 57.3 \\
\hline
\end{tabular}


Note: For the categories presented in this study, the condom category constitutes both the male and female condom and the sterilisation category includes both the male and female sterilisation. Other modern methods include, diaphragm,

norplant/ implants, form and jelly, and standard days method.

The results in Table 3 show that women are more likely to discontinue use of a method in rural areas than in urban areas. Generally, duration of use of a method is shorter in rural areas compared to urban areas. Likewise, women with higher education attainment were less likely to discontinue use of a contraceptive method. Surprisingly, women with no education seem to use condoms more than their counterparts from other education categories.

These findings point to a major problem discontinuation of contraceptive methods among married women. Although, a small proportion of married women were using the IUD, women using such a method are less likely to discontinue its use compared to other modern methods. The results in Table 3 show that half of the women are still using the injectable method after seven months. Unlike the 20II data, the estimates from the 2006 data points to higher discontinuations rates among women using the condom compared to other modern methods of contraception. This we anticipate inconsistencies in use and keeping track of the frequency and duration of use of barrier methods. Discontinuation of the IUD is generally lower as compared to other modern methods.

Table 3: Median duration of method specific use in months by type of place of residence and education, Uganda

\begin{tabular}{|c|c|c|c|c|c|c|c|c|c|c|c|c|}
\hline \multirow{3}{*}{$\begin{array}{l}\text { Background } \\
\text { factors }\end{array}$} & \multicolumn{12}{|c|}{ Median duration of contraceptive methods before discontinuation } \\
\hline & \multicolumn{2}{|c|}{ All methods } & \multicolumn{2}{|c|}{ Pill } & \multicolumn{2}{|c|}{ IUD } & \multicolumn{2}{|c|}{ Injection } & \multicolumn{2}{|c|}{ Condom } & \multicolumn{2}{|c|}{$\begin{array}{l}\text { Other } \\
\text { modern }\end{array}$} \\
\hline & 2006 & 2011 & 2006 & 2011 & 2006 & 2011 & 2006 & 2011 & 2006 & 2011 & 2006 & 2011 \\
\hline Residence & & & & & & & & & & & & \\
\hline Urban & 7.2 & 12.5 & 7.0 & 11.4 & 32.5 & 14.0 & 7.1 & 9.9 & 7.3 & 16.0 & 32.3 & 27.1 \\
\hline Rural & 8.0 & 9.7 & 8.0 & 7.6 & 20.7 & 55.0 & 7.2 & 8.3 & 5.6 & 17.2 & 18.9 & 12.8 \\
\hline Education & & & & & & & & & & & & \\
\hline $\begin{array}{l}\text { No } \\
\text { education }\end{array}$ & 9.5 & 10.6 & 10.4 & 5.8 & - & - & 6.6 & 10.3 & 10.0 & 18.5 & - & 29.3 \\
\hline $\begin{array}{l}\text { Primary } \\
\text { Secondary }\end{array}$ & $\begin{array}{l}7.0 \\
9.7\end{array}$ & $\begin{array}{r}9.6 \\
11.4\end{array}$ & $\begin{array}{r}5.6 \\
12.3\end{array}$ & $\begin{array}{r}8.8 \\
10.4\end{array}$ & 47.5 & $\begin{array}{l}56.8 \\
14.0\end{array}$ & $\begin{array}{r}6.6 \\
11.4\end{array}$ & $\begin{array}{l}8.0 \\
9.3\end{array}$ & $\begin{array}{l}5.7 \\
5.4\end{array}$ & $\begin{array}{l}15.9 \\
16.4\end{array}$ & $\begin{array}{l}15.0 \\
26.9\end{array}$ & $\begin{array}{l}13.5 \\
15.5\end{array}$ \\
\hline Higher & 10.1 & 14.6 & 15.4 & 12.6 & 31.3 & 14.0 & 7.9 & 11.9 & 11.8 & 16.9 & 38.9 & 26.5 \\
\hline Total & 7.9 & 10.7 & 7.5 & 9.8 & 22.1 & 14.8 & 7.3 & 8.7 & 5.8 & 16.0 & 24.5 & 16.7 \\
\hline
\end{tabular}

Note: We exclude sterilization because it is a permanent irreversible contraceptive method

An increase in the use of contraceptives has been shown to significantly reduce maternal deaths in developing countries, improve child survival, increase birth weight, reduce unsafe induced abortion among other things (Marston and Cleland 2003; Cleland, Conde-Agudelo, Peterson et al. 20I2). However, this has not been always the case in most developing nations where discontinuation rates are still high. In such settings women face a high risk of exposure to unintended pregnancies and poor maternal health. The results in Table 3 highlight the need to promote continuous use of modern methods once married women start using them. For example, the analyses from the 201I data show that women prefer using the injection most to other modern methods of contraception. However, this method is one of the most discontinued modern methods among Ugandan married women after 12 months of use. However, among other reasons, some of these women who have stopped using the injections switch to other modern methods - reversible or permanent. We give an account of the switching pattern at 3 months in Table 4 because switching of methods is more likely to occur after three months of starting use following discontinuation (Ali and Cleland 20lob). More women switched to traditional methods than modern methods after three months of using the injection. The results in Table 4 still show higher discontinuation rates among women 
using the injection method in rural than in urban

areas.

Table 4: Switching status at 3 months after discontinuing the injection by type of residence and education, Uganda 20I I

\begin{tabular}{|c|c|c|c|c|c|c|c|c|c|}
\hline \multirow[b]{2}{*}{$\begin{array}{l}\text { Background } \\
\text { factors }\end{array}$} & \multirow[b]{2}{*}{$\begin{array}{l}\text { At } \\
\text { risk }\end{array}$} & \multirow[b]{2}{*}{$\begin{array}{l}\text { Became } \\
\text { pregnant }\end{array}$} & \multicolumn{7}{|c|}{ Switched to } \\
\hline & & & Pill & IUD & Condom & $\begin{array}{l}\text { Steriliz- } \\
\text { ation }\end{array}$ & $\begin{array}{l}\text { Other } \\
\text { modern }\end{array}$ & & $\begin{array}{l}\text { Traditio- } \\
\text { nal }\end{array}$ \\
\hline \multicolumn{10}{|l|}{ Residence } \\
\hline Urban & 12.7 & 1.8 & - & & - & - & - & 0.9 & \\
\hline Rural & 13.7 & 0.5 & - & & - & - & - & - & 1.5 \\
\hline \multicolumn{10}{|l|}{ Education } \\
\hline No education & 6.5 & - & - & & - & - & - & - & - \\
\hline Primary & 16.0 & 0.5 & - & & - & - & - & - & 1.6 \\
\hline Secondary & 11.7 & 2.4 & - & & - & - & - & 1.2 & - \\
\hline Higher & - & - & - & & - & - & - & - & - \\
\hline Total & 13.3 & 0.94 & - & & - & - & - & 0.3 & 1.0 \\
\hline
\end{tabular}

Note: The category of traditional methods includes periodic abstinence, withdrawal and lactational amenorrhoea.

Table 5 shows a positive association between the level of women's education and starting to use a contraceptive method. We anticipate better knowledge about delaying or avoiding child bearing among the better educated women compared to women with less education. The same reason could also hold for a woman's type of place of residence - more women start using a contraceptive method in urban than in rural areas.
The general picture from the results in Table 5 is, women are more likely to use the injectable as compared to other modern methods. The results below show that none of the women who has never used a modern method is likely to start using the IUD for the first time. As discussed above, low use of a modern contraceptive method among women residing in rural areas remains a serious challenge.

Table 5: Proportion of women starting to use a modern method after 12 months of not using, Uganda

\begin{tabular}{|c|c|c|c|c|c|c|c|c|c|c|c|c|}
\hline \multirow{2}{*}{$\begin{array}{l}\text { Background } \\
\text { factors }\end{array}$} & \multicolumn{2}{|c|}{ All methods } & \multicolumn{2}{|c|}{ Pill } & \multicolumn{2}{|c|}{ Injection } & \multicolumn{2}{|c|}{ Condom } & \multicolumn{2}{|c|}{ Sterilization } & \multicolumn{2}{|c|}{$\begin{array}{l}\text { Other } \\
\text { modern }\end{array}$} \\
\hline & 2006 & 2011 & 2006 & 2011 & 2006 & 2011 & 2006 & 2011 & 2006 & 2011 & 2006 & 2011 \\
\hline Urban & 45.7 & 59.4 & 22.0 & 16.9 & 17.2 & 35.7 & 7.7 & 6.5 & 1.4 & 2.3 & 1.2 & 2.8 \\
\hline Rural & 29.0 & 48.0 & 4.3 & 4.9 & 13.4 & 35.7 & 4.2 & 4.7 & 0.8 & 4.1 & 0.8 & 1.2 \\
\hline \multicolumn{13}{|l|}{ Education } \\
\hline Noeducation & 12.6 & 39.0 & 0.4 & 7.4 & 7.4 & 33.1 & 0.4 & - & 0.7 & - & - & 0.5 \\
\hline Primary & 30.1 & 45.9 & 5.5 & 5.9 & 13.9 & 34.0 & 3.6 & 1.8 & 0.9 & 3.9 & 0.8 & 1.3 \\
\hline Secondary & 53.3 & 58.4 & 17.6 & 14.0 & 20.2 & 37.7 & 15.4 & 7.4 & 1.2 & 3.8 & 1.8 & 2.1 \\
\hline Higher & 76.5 & 77.8 & 30.2 & 15.5 & 40.0 & 44.5 & 16.4 & 29.5 & - & 4.0 & 5.3 & 5.5 \\
\hline Total & 31.1 & 51.8 & 6.5 & 8.9 & 13.8 & 35.7 & 4.6 & 5.3 & 0.9 & 3.6 & 0.8 & I.7 \\
\hline
\end{tabular}

Note: No woman reported to having started using an IUD after 12 months from both surveys

\section{Discussion and Conclusion}

Non-use and discontinuation of reversible modern contraceptive methods remain challenges in implementing family planning programmes in subSaharan Africa. The inclusion of calendar data in DHS surveys provides an important data source in examining contraceptive use dynamics among populations of high contraceptive discontinuation and switching (Callahan and Becker 20I2).

This paper has examined contraceptive use dynamics using an exploratory approach among Ugandan women. For the estimates, we have presented discontinuation rates after 12 months of 
use and switching patterns at 3 months after stopping use of a method. We also present median durations of use of different methods. The pill and the injectable appear to be the most preferred modern contraceptive methods used by Ugandan married women. Despite this observation, our results show that women are more likely to stop using such methods especially the injectable as compared to other modern methods. Our interest then was to investigate the switching status of women who stopped using the injection method. The results indicate that most women who discontinue use of the injection at three months either practice periodic abstinence or withdrawal.

Using survival models, calendar data indicate that discontinuation of modern methods remains a challenge in implementing family planning programmes among married women in Uganda. However, the results indicate a decrease in the proportion of women who have never used a modern method in a ten-year period. As Laguna and colleagues (2000) emphasize, there is need to encourage women to start using at least a modern method.

Our results also confirm that women in rural areas are more likely to discontinue use of a method than women in urban areas. Low contraceptive use means that women would have high exposure periods to unintended or mistimed pregnancies (Bellizzi, Sobel, Obara et al. 2015). The results from the analyses point to the urgent need to address the problem of discontinuing use of modern reversible methods. Stopping use of a method and ineffective switching means that married women in the reproductive age group are exposed to a high risk of conceiving mistimed or unwanted children.

Bellizzi and colleagues (20/5) suggest that more attention should be given to health concerns such as side effects in programmes geared toward increasing uptake of modern contraceptives, thereby reducing discontinuation rates. The other conclusion we draw from the study is that women with less education attainment still experience challenges in starting and continuing to use modern methods of contraception. Reasons related to access and health concerns might play a significant role. Such evidence would mean that programme managers and enforcers of contraceptive use are then able to highlight programme challenges and strengthen fertility reduction programmes.

In this study, we provide evidence that education plays a major role in influencing contraceptive use. The study has showed that women with more education are less likely to discontinue use of a modern method compared to women with less education. Increased contraceptive use would help to reduce fertility. Although stopping use of modern methods remains a challenge in achieving desired fertility, discontinuation of modern methods has reduced slightly between the year $200 \mathrm{I}$ and $20 \mathrm{ll}$. It is recommended, based on the findings, that more effective programmes are needed for better product availability and full access to modern contraception among Ugandan married women so as to restrain high discontinuation rates among users. More product availability might also lead to effective switching.

\section{References}

Ali, M and J Cleland. 1995. Contraceptive discontinuation in six developing countries: A cause-specific analysis, International Family Planning Perspectives 2I(3): 92-97. doi: http://dx.doi.org//0.2307/2 / 33 /81

Ali, MM and J Cleland. 1999. Determinants of contraceptive discontinuation in six developing countries, Journal of Biosocial Science 31 (3): 343-360.

doi: http://dx.doi.org/I0.1017/S0021932099003430

Ali, MM and J Cleland. 2010a. Contraceptive switching after method-related discontinuation: Levels and differentials, Studies in Family Planning $4 \mathrm{I}(2)$ : I29-I33. doi: http://dx.doi.org/I0.1 I I I/j. I 728-

4465.20I0.00234.x

Ali, MM and J Cleland. 2010b. Oral contraceptive discontinuation and its aftermath in 19 developing countries, Contraception $81(2010)$ : 22-29. doi: http://dx.doi.org//0.1016/j.contraception.2009. 06.009

Ali, MM, J Cleland, and IH Shah. 2003. Trends in reproductive behaviour among young single women in Colombia and Peru: 1985-1999, Demography 40(4): 659-673. doi: http://dx.doi.org//0.1353/dem.2003.003 I

Ali, MM, J Cleland, and IH Shah. 20I2. Causes and consequences of contraceptive discontinuation: evidence from 60 demographic and health surveys. Geneva, Switzerland: World Health Organization.

Available: http://apps.who.int/iris/bitstream/I0665/75429/ I/978924I504058_eng.pdf Accessed 22 May 2015

Allendorf, K. 20I2. Women's agency and the quality of family relationships in India, Population Research and Policy Review 3I(2): |87-206. doi: http://dx.doi.org//0.1007/s I I | 30। 2-9228-7 
Barden-O'Fallon, JL, IS Speizer, and JS White. 2008. Association between contraceptive discontinuation and pregnancy intentions in Guatemala, Revista Panamericana de Salud Pública 23(6): 4/0-4/7. doi: http://dx.doi.org/10.1590/S102049892008000600006

Bellizzi, S, HL Sobel, H Obara, and M Temmerman. 2015. Underuse of modern methods of contraception: underlying causes and consequent undesired pregnancies in 35 lowand middle-income countries, Human Reproduction 30(4): 973-986. doi: http://dx.doi.org// 0.1093/humrep/deu348

Blanc, AK and AA Way. 1998. Sexual behavior and contraceptive knowledge and use among adolescents in developing countries, Studies in Family Planning 29(2): 106-II6. doi: http://dx.doi.org//0.2307// 72/53

Bongaarts, J. 2010. The causes of educational differences in fertility in sub-Saharan Africa Vienna Yearbook of Population Research, Education and Demography 8: 31-50. doi: http://dx.doi.org//0.1553/populationyearbook2 $010 s 31$

Bradley, SEK, HM Schwandt, and S Khan. 2009. Levels, trends, and reasons for contraceptive discontinuation. Calverton, Maryland, USA: ICF Macro. Available: http://dhsprogram.com/pubs/pdf/AS20/AS20.pdf Accessed I 3 January 2016

Bruce, J. 1990. Fundamental elements of the quality of care: a simple framework, Studies in Family Planning 2I(2): 6I-9l. doi: http://dx.doi.org// 0.2307// 966669

Caldwell, JC. 1980. Mass education as a determinant of the timing of fertility decline, Population and Development Review 6(2): 225255. doi: http://dx.doi.org// 0.2307/1972729

Callahan, RL and S Becker. 20I2. The reliability of calendar data for reporting contraceptive use: Evidence from rural Bangladesh, Studies in Family Planning 43(3): 2/3-222. doi: http://dx.doi.org/10.1 I I I/j. I 7284465.20I2.003/9.x

Cleland, J and MM Ali. 2004. Reproductive consequences of contraceptive failure in 19 developing countries, Obstetrics and Gynecology 104(2): 314-320. doi: http://dx.doi.org//0.1097/0 I.AOG.0000 I 34789. 73663.fd

Cleland, J, A Conde-Agudelo, H Peterson, J Ross, and A Tsui. 2012. Contraception and health, The Lancet 380(9837): 149-156. doi: http://dx.doi.org/10.1016/S01406736(I2)60609-6
Cleves, MA, WW Gould, RG Gutierrez, and YV Marchenko. 2010. An Introduction to Survival Analysis Using Stata. Texas: A Stata Press Publication, Stata Corporation, College Station.

Curtis, S, E Evens, and W Sambisa. 20II. Contraceptive discontinuation and unintended pregnancy: An imperfect relationship, International Perspective on Sexual and Reproductive Health 37(2): 58-66. doi: http://dx.doi.org//0.1363/37058I I

Curtis, SL and CR Hammerslough. 1995. Model further analysis plan: Contraceptive use dynamics. Calverton, Maryland, USA: Macro International.

Available: http://dhsprogram.com/pubs/pdf/FA59/FA59.pd f Accessed I 4 March 2016

Darroch, JE. 20I3. Trends in contraceptive use, Contraception 87(3): 259-263. doi: http://dx.doi.org//0.1016/j.contraception.2012. 08.029

Darroch, JE and S Singh. 20/3. Trends in contraceptive need and use in developing countries in 2003, 2008, and 2012: an analysis of national surveys, The Lancet 38I: |756-1762. doi: http://dx.doi.org//0.1016/S0I406736(I3)60597-8

DeRose, LF and AC Ezeh. 2010. Decision-making patterns and contraceptive use: Evidence from Uganda, Population Research and Policy Review 29(3): 423-439. doi: http://dx.doi.org/|0.1007/s | | | |3-009-9|5|-8

Garenne, M and V Joseph. 2002. The timing of the fertility transition in sub-Saharan Africa, World Development 30(10): 1835-1843. doi: http://dx.doi.org/10.1016/S0305750X(02)00069-4

Habumuremyi, PD and M Zenawi. 2012. Making family planning a national development priority, The Lancent 380(9837): 78-80. doi: http://dx.doi.org/10.1016/S0I406736(I2)60904-0

Kabagenyi, A, P Ndugga, S Ojiambo, and B Kwagala. 20l4b. Modern contraceptive use among sexually active men in Uganda: does discussion with a health worker matter?, BMC Public Health 14(286): I-18. doi: http://dx.doi.org//0.1 |86//47|-2458-I4-286

Kravdal, $\varnothing$. 2002. Education and fertility in subSaharan Africa: Individual and community effects, Demography 39(2): 233-250. doi: http://dx.doi.org/I0.1353/dem.2002.00I7

Laguna, EP, ALC Po, and AE Perez. 2000. Contraceptive use dynamics in the Philippines: Determinants of contraceptive method choice and discontinuation. Calverton, Maryland: ORC Macro. 
Marston, C and J Cleland. 2003. Relationships between contraception and abortion: A review of the evidence International Family Planning Perspectives 29(I): 6-13. doi: http://dx.doi.org//0.2307/3 | 80995

Meekers, D and RV Rossem. 2005. Explaining inconsistencies between data on condom use and condom sales, BMC Health Services Research 5(5): I-I4. doi: http://dx.doi.org// 0. I I86/I472-6963-5-5

Minnis, AM, Avd Straten, C Gerdts, and NS Padian. 2010. A comparison of four condom-use measures in predicting pregnancy, cervical STI and HIV incidence among Zimbabwean women,

Sexually Transmitted Infections 86(3): 23|-235. doi: http://dx.doi.org/ | 0.1 | 36/sti.2009.03673 I

Moultrie, TA and IM Timæus. 20I5. Intervals, intentions, and institutions: Three important neglected considerations in understanding the African fertility transition. . Paper presented at the National Research Council Committee on Population Workshop on Recent Trends in Fertility in sub-Saharan Africa,. Washington DC, June I5-16, 2015.

Ping, T. 1995. IUD discontinuation patterns and correlates in four counties in North China, Studies in Family Planning 26(3): 169-179. doi: http://dx.doi.org//0.2307/2/37835

Reynolds, HW, W Luseno, and IS Speizer. 2012. The measurement of condom use in four countries in East and Southern Africa, AIDS and Behavior 16(4): 1044-1053. doi: http://dx.doi.org//0.1007/s |046I-0 I 2-0|46-9

Seltzer, JR. 2002. The Origins and Evolution of Family Planning Programs in Developing Countries. RAND Corporation. Available: http://www.rand.org/content/dam/rand/pubs/m onograph_reports/2007/MRI276.pdf. Accessed 27 January 2016

Skiles, MP, M Cunningham, A Inglis, B Wilkes, B Hatch, A Bock, et al. 2015. The effect of access to contraceptive services on injectable use and demand for family planning in Malawi, International Perspectives on Sexual and Reproductive Health 4I(I): 20-30. doi: http://dx.doi.org/I0.1363/4102015

Steele, F and S Curtis. 2003. Appropriate methods for analyzing the effect of method choice on contraceptive discontinuation, Demography 40(I): I-22. doi: http://dx.doi.org/l0.1353/dem.2003.0009

Timæus, IM and TA Moultrie. 2008. On postponement and birth intervals, Population and Development Review 34(3): 483-5I0. doi: http://dx.doi.org// 0.1 I I I/j. I 7284457.2008.00233.x

Tsui, AO. 200I. Population policies, family planning programs, and fertility: The record, Population and Development Review 27: 184-204. doi:

Uganda Bureau of Statistics (UBOS) and ICF International Inc. 2012. Uganda Demographic and Health Survey, 20II Calverton, Maryland: UBOS and ICF International Inc.

United Nations Population Division. 2015a. 2015 Update for the MDG Database: contraceptive prevalence (POP/DB/CP/A/MDG20I5). UN Department of Economic and Social Affairs

United Nations Population Division. 2015d. Trends in Contraceptive Use Worldwide 2015. UN Department of Economic and Social Affairs. Available:

http://www.un.org/en/development/desa/popul ation/publications/pdf/family/trendsContraceptiv eUse2015Report.pdf Accessed II March 2016.09 .26 